\title{
O IMPACTO DO MEDO NAS RELAÇÕES INTERPESSOAIS
}

\author{
The fear's impact on interpersonal relationships
}

Gabriela Monteiro de Araújo - Universidade Presbiteriana Mackenzie /Brasil Maria Regina Brecht Albertini - Universidade Presbiteriana Mackenzie /Brasil

RESUMO: É significativo estudar como o medo impacta as relações interpessoais a partir de memórias que podem recriar sensações vividas anteriormente. A sociedade contemporânea estimula os sujeitos a eliminar experiências traumáticas e obter controle das circunstâncias da vida. Com isso, as relações interpessoais têm sido baseadas em responder às necessidades do sujeito em detrimento do compromisso para com o outro. Objetivo: Explorar como o medo impacta nas relações interpessoais. Método: Estudo exploratório com análise qualitativa dos dados. Foram realizadas 5 entrevistas semiestruturadas com psicólogos clínicos que atendem o público adulto. Resultados: $\mathrm{O}$ medo manifesta-se principalmente por sintomas de angústia e ansiedade no contexto clínico. Os sujeitos se pautam na sensação de experiências anteriores e acabam prédeterminando a sensação de situações ainda não vividas. É mantido, portanto, um padrão de comportamento que gera um padrão nos relacionamentos. A clínica, portanto, poderá proporcionar o desenvolvimento do "eu" para que se alcance a integração. Conclusão: $O$ indivíduo pautado pelo medo estará sujeito a viver um distanciamento da autenticidade e originalidade das vinculações. $\mathrm{O}$ ciclo de repetição se manterá e promoverá a estagnação do sujeito frente ao movimento de ir ao encontro de novas vivências e relações. Com isso, é importante que o psicólogo clínico se atente ao medo e ao contexto sociocultural para proporcionar o fortalecimento do sujeito.

Palavras-chave: Medo. Relações interpessoais. Sociedade contemporânea.

ABSTRACT: It is meaningful to study how fear impacts on people's relationships from memories that can recreate previously lived sensations. Contemporary society stimulate individuals to finish traumatic experiences and take over control of life's circumstances. Because of this, interpersonal relationships have been based on corresponding one's needs despite the commitment to the other person. Research Goal: Explore how fear impacts interpersonal relationships. Methodology: This is an exploratory study based on qualitative data analyses, relied on 5 semi-structured interviews with clinical psychologists who attends to adults. Results: The fear manifests itself, mainly, by symptoms of anguish and anxiety in clinical context. The subjects based themselves on previous sensations and end up pre-determining the sensation of situations not yet lived. It is maintained, therefore, a behavior standard that creates a relationship pattern. As a result, the clinic can provide the "self-development" in order to achieve the integration. Conclusion: The individual guided by fear will be subject to live with a distance from authenticity and originality of the connections. The cycle will maintain and promote the subject's stagnation against the opening movement of getting new experiences and relationships. Consequently, it is important that the clinical psychologist be aware of fear and the sociocultural context to provide the subject's strengthening.

Keywords: Fear. Interpersonal relationships. Contemporary society. 


\section{INTRODUÇÃO}

Quando o tema do medo é abordado, evidencia-se que esse é um amplo e profundo assunto tendo em vista a ambiguidade entre a intemporalidade do medo como afeto fundamental e a atualidade em se abordar essa temática. Isso se deve ao fato de que é consensual a sensação de sentir medo e, com isso, os sentimentos de angústia e insegurança advindos da experiência de ter sentido essa emoção. Quando se fala de medo, refere-se à exigência de um objeto, ao qual irá dirigir sua atenção (VANIER, 2006). Porém, iremos tratar neste trabalho a respeito dos medos sentidos a partir de memórias que recriam a sensação vivida frente ao objeto de medo, ou seja, a forma com que os indivíduos passam a viver pautados em suas vivências anteriores.

Tem-se que as experiências traumáticas vividas nos momentos em que o medo foi experienciado diretamente devem ser eliminadas (visão da sociedade contemporânea). Dessa forma, é plausível compreender a ânsia contemporânea em minimizar erros, contornar situações tidas como inovadoras, permanecer na zona de conforto e, principalmente, buscar o controle tanto das circunstâncias quanto, até mesmo, das pessoas e das relações interpessoais. Considerando essa busca desenfreada da atualidade, deparase com a questão de que "só temos medo verdadeiramente daquilo que não podemos compreender" (MAUPASSANT, 1884/1979 apud VANIER, 2006, p. 291). A pósmodernidade traz consigo a ambivalência entre sujeitos que ambicionam compulsivamente novidades, vivenciar acontecimentos inéditos e surgimento de ocorridos inusitados. Contudo, a partir do momento que a vida exige uma atitude de fato inovadora e autêntica, os indivíduos não estão preparados para tal, pois dar esse passo implica em ir rumo ao desconhecido, ao novo, o que, mais uma vez, causa angústia.

A contradição entre a ambição por segurança, ter ao máximo poder sobre as circunstâncias e a imprevisibilidade inerente da vida, pode causar paralisação dos seres frente às situações. Dessa forma, conseguimos notar na contemporaneidade que as pessoas preferem abrir mão da sua liberdade para fugir do medo (CERVANTES apud KARNAL, 2018). É mais simples abrir mão da liberdade e ter alguém que tome as atitudes no lugar do indivíduo e, sendo assim, terceirizar a garantia que se busca por segurança, do que ter que assumir as responsabilidades por si só e, com isso, ter uma postura ativa frente aos desafios do dia a dia.

Educação, Psicologia e Interfaces, Volume 3, Número 3, p. 79-93, Setembro/Dezembro, 2019. 
Essas buscas têm se refletido fortemente nas relações interpessoais. Os relacionamentos, sejam eles familiares, amigáveis ou afetivos, não têm mais se respaldado no compromisso e na vivência da unicidade de uma pessoa para com a outra. Infelizmente, a característica produtiva e utilitária tomou conta dos relacionamentos. A originalidade das circunstâncias e das relações aos poucos é perdida devido ao hábito concebido através do medo derivado desenvolvido frente a uma situação possível de perigo.

A partir dessas reflexões, é possível considerar o desenvolvimento e a legitimação de relações mais superficiais e distantes do real. Todo o contexto contemporâneo vivido pelo sujeito favorece que este viva sendo reforçado por relações cada vez mais utilitárias. Já não há importância se está se estabelecendo uma relação com o real ou verdadeiro, desde que essa relação responda as expectativas e necessidades daquele momento e, também, traga a sensação de satisfação e pertencimento tanto almejadas. Contudo, esses anseios apenas distanciam as pessoas delas mesmas e de poderem viver relações carregadas de plenitude e verdade.

A partir da investigação das principais ambições e queixas advindas das experiências e ansiedades relativas ao medo subjetivo e/ou derivado, é notório o estabelecimento de máscaras as quais o sujeito esconde-se para não deparar-se com seu próprio eu e, a partir de então, encontrar com o que há de verdadeiro, intenso e genuíno no outro. O presente estudo busca, portanto, perceber o funcionamento psíquico frente a essas realidades, dialogando com as questões de superficialidade vivida e, indiretamente buscadas pelas pessoas. Juntamente, analisar o impacto que ir ao encontro do novo, do desconhecido pode causar sobre o indivíduo. Esse trabalho também irá explorar o que leva as pessoas a abrirem mão de sua liberdade, na busca pela segurança e controle acima de qualquer premissa e, por fim, investigar como o medo impacta nas relações interpessoais.

\section{MATERIAL E MÉTODO}

O presente trabalho foi realizado através de procedimentos exploratórios para que, segundo Gil (2002), haja maior familiaridade com o problema levantado, e assim, seja possível construir hipóteses.

Foi realizada uma pesquisa bibliográfica através da revisão em materiais já elaborados. Para essa revisão foram levantados 17 artigos acadêmicos, 13 livros, 2 
dissertações e 1 link retirado da internet dos últimos cinco anos. Destes, foram utilizados 9 artigos acadêmicos, 8 livros, 1 dissertação de mestrado e 1 link da internet. Ademais, foram efetuadas 5 entrevistas semiestruturadas para coletar dados com psicólogos clínicos de abordagem psicanalítica formados que atendam adultos.

\subsection{Procedimentos}

A pesquisa foi realizada com as entrevistas semiestruturadas com os profissionais que atuam no contexto clínico atendendo ao público adulto. Foram convidados cinco psicólogos para participarem das entrevistas semiestruturadas. A entrevista foi realizada pela pesquisadora responsável, os dados foram coletados presencialmente e, após terem sido levantadas as bibliografias, foi efetuada uma análise qualitativa dos resultados obtidos nas entrevistas.

A entrevista era composta por 5 questões: Como podem ser identificadas as queixas relacionadas ao medo? De que forma elas são suscitadas? Com qual frequência? Quais as condutas utilizadas para o tratamento dessa temática? Como você percebe, na clínica, que o medo pode interferir nas relações interpessoais? Quais os recursos comumente buscados pelos pacientes? Você, como psicanalista, acredita que as exigências da sociedade contemporânea influenciam na forma como os indivíduos têm experienciado e internalizado o medo? Ele pode ser visto mais como uma questão social ou como característica da personalidade da pessoa?

\section{RESULTADOS E DISCUSSÃO}

Os sintomas que surgem no contexto clínico, dizem respeito a medos, sentimentos e emoções muitas vezes desconhecidos dos sujeitos. As entrevistas realizadas trouxeram que essas queixas podem ser expressas como dificuldade em simbolizar; sentimentos de impotência que seria a dificuldade que a pessoa tem em perceber em si recursos para enfrentar esses sentimentos; falta de força para enfrentar a realidade; necessidade de controle; medo do futuro; impedimento em relações; impedimento em executar tarefas; repetição de conteúdos; expectativa; risco iminente e dificuldade de processos identificatórios. Todos esses apontamentos pontuam características difusas e distantes da realidade concreta e pragmática da vida humana. Dessa forma, segundo Bauman (2012, p. 7): “'medo' é o nome que damos a nossa incerteza: nossa ignorância da ameaça e do 
que deve ser feito - do que pode e do que não pode - para fazê-la parar ou enfrentá-la, se cessá-la estiver além do nosso alcance".

O medo em si é suscitado através de sentimentos de angústia e ansiedade, sendo este, por exemplo, atualmente considerado como mal do século. Através desses sintomas levantados de modo consciente ou inconsciente, pode-se notar uma associação direta que é feita pela psique: situação vivida $\rightarrow$ medo; situação hipotética $\rightarrow$ medo derivado.

Essa associação evidencia um padrão de comportamento. É importante distinguir as influências advindas do histórico e do contexto do indivíduo, mas sendo natural e lícita essas influências, do padrão de comportamento e, consequentemente, o seu ciclo de repetição gerado patologicamente que pode acabar desviando o sujeito de sua originalidade e criatividade. Segundo os conceitos winnicottianos, o sujeito precisa aprimorar as funções do desenvolvimento emocional primitivo para que ele consiga atingir o amadurecimento emocional e, com isso, suporte as frustrações e consiga ter recursos para enfrentar as situações da realidade.

Uma das psicólogas participantes pontua que o sujeito pode demonstrar o seu medo como uma ansiedade persecutória, em que ele se sente como vítima do seu ambiente, ou como ansiedade depressiva, em que ele se vê como culpado por atacar seu objeto de amor. O início do seu desenvolvimento emocional está marcado pela integração com a mãe, em que esta supre todas as necessidades do bebê. É justamente a falha do ambiente (mãe) nesse processo de desintegração que vai impactar na forma como o indivíduo terá desenvolvido suas estruturas psíquicas.

Esses apontamentos evidenciam que muitos dos quesitos relativos ao surgimento do medo e dos sintomas de ansiedade podem ser associados às falhas no desenvolvimento primitivo do sujeito que ocorreram no seu contato com a mãe, segundo Winnicott. Nesta falha, pode-se dizer que estão contidos diversos sintomas, que o indivíduo em algum momento irá demonstrar, que dizem respeito ao não desenvolvimento do seu eu integrado e não preparo para as falhas advindas do ambiente. Com isso, as experiências traumáticas ou que ao menos proporcionaram sentimentos ruins foram vivenciadas sem a devida estrutura psíquica para o enfrentamento. A partir de então, possivelmente o sujeito pautado pela sua experiência, tenderá a manter um ciclo de repetição em seu comportamento frente ao ambiente e às demais vinculações que ele teria possibilidade de estabelecer. 
No contexto clínico é possível perceber, de acordo com uma das participantes, que os sujeitos apresentam queixas que denotam um medo em função de crescer, se independer e se responsabilizar. Pondé discute, a partir da perspectiva winnicottiana, a respeito do conceito de saúde em que esta é considerada como "ter a possibilidade de viver suas próprias experiências de forma criativa e espontânea e ser responsável por elas, experimentando um sentido de realidade "segura", sem o medo interno de um possível colapso" (PONDÉ, 2012, p. 57).

Os sujeitos que passam a viver dessa forma, em que o seu falso self vira protagonista do viver dele, denotam um medo como apreensão em relação ao futuro, segundo dados colhidos em entrevista. As experiências angustiantes vivenciadas se sobressaem e, com isso, o indivíduo apresenta grandes dificuldades em sair da paralisação do medo do que está por vir, que poderiam ser novas experiências ou novos relacionamentos. Uma das participantes ressalta que "pode-se dizer que todo paciente tem um medo, o que difere é o tipo de ansiedade subjacente à este medo" (sic). Portanto, fica claro que esse tipo de queixa manifesta-se de forma onipresente na clínica.

Considerando o contexto clínico e pautando-se na clínica winnicottiana, o trabalho desenvolvido para conduzir o tratamento sobre as queixas relacionadas ao medo e seus contextos, será focado nas funções do desenvolvimento emocional primitivo. Dessa forma, o psicólogo clínico utilizará as técnicas de holding (sustentação) e handling (manejo) para conduzir o tratamento do sujeito, além de outras técnicas mais. Os psicólogos clínicos de alguma forma deverão trabalhar com as demandas que os indivíduos trazem como dificuldades em lidar com o ambiente. Segundo Safra (1999), é importante no manejo clínico que o psicólogo respeite o tempo que o paciente pode levar para estar preparado para tocar e trabalhar as suas questões.

O manejo clínico em Winnicott aponta a relevância do analista intervir com a "sustentação da situação clínica no tempo, dando as condições para o aparecimento do gesto criativo do paciente" (SAFRA, 1999, p. 3). É através do aparecimento desse gesto criativo que o sujeito desenvolverá a integração do seu eu, ou seja, o contato com seu verdadeiro self.

O contexto clínico deve auxiliar o indivíduo a alcançar o insight cognitivo. Este, de acordo com alguns participantes, seria o fato de organizar quais objetos se tem medo e, para isso, é preciso localizar e compreender a origem desse medo e como ele pode 
impactar nas relações e no contexto de vida atual desse sujeito. A partir desse movimento, o processo será em direção à elaboração, a qual busca-se desenvolver estratégias no sentido afetivo e prático (considerando o contexto do indivíduo, seus afetos e sua individualidade), para sair do ciclo de comportamentos repetitivos. Esse processo pode ser elaborado inicialmente através de "narrativas a respeito daquilo que gere menos sofrimento do que as atuais" (sic).

Nas entrevistas realizadas, foi possível perceber o grande impacto que as questões relativas ao medo têm sobre os indivíduos e sobre a forma como estes irão se relacionar e se vincular. Essas características passarão a influenciar os relacionamentos a partir do momento em que elas são advindas de uma falta de autoconhecimento para saber lidar com seus limites e capacidades, para assim, saber como se posicionar frente ao outro.

Os dados apontam que os sujeitos demonstram, muitas vezes, um padrão de comportamento que, consequentemente, promovem um padrão de relacionamento. $\mathrm{O}$ padrão de comportamento pode estar relacionado a um medo que, como na maioria das formas como este se manifesta, é paralisante. Essa paralisia, por sua vez, ocorre quando o sujeito busca evitar a situação que gera angústia e sofrimento, como elencado por uma das participantes. O padrão de relacionamento, além das questões unicamente relacionadas ao indivíduo, pode estar pautado na transmissão transgeracional, dependendo do contexto histórico-familiar desse indivíduo.

O movimento contra a hipótese de vir a sentir medo também manifesta-se na busca exacerbada pelo acerto e, em paralelo, na demonstração de que este não é um anseio demasiado. "O medo de se vincular ao medo do sofrimento" (SMEHA; OLIVEIRA, 2013, p. 8). Uma das entrevistadas ressaltou que os pacientes têm demonstrado bastante cautela em seus relacionamentos sendo que, demonstram uma indiferença, mas na verdade essa indiferença nada mais é do que um mecanismo de defesa para não acessar seus verdadeiros sentimentos. Devido a essas características, os sujeitos aderem facilmente às propostas contemporâneas que maximizam a individualidade e, por isso, eliminam o compromisso e a dependência nos relacionamentos interpessoais. Os laços nas relações apresentam-se mais frouxos e podem ser desfeitos a qualquer momento, o que denota um sentimento de insegurança e incerteza contidos nos relacionamentos (SCHMITT; IMBELLONI, 2011).

"Um padrão traumático provoca a perda da continuidade de ser, o que leva a um estado de "agonias impensáveis"” (PONDÉ, 2012, p. 44). O indivíduo, portanto, começa 
a viver de uma forma insustentável em que, por um lado nega o seu verdadeiro eu e se distancia do contato consigo mesmo e, por outro lado, sustenta relações não saudáveis e não autênticas. Gera-se, assim, vínculos mórbidos os quais ou o sujeito patologiza no sentido depressivo (busca função de completude do outro) ou no sentido persecutório (outro como objeto de ameaça).

Um dos participantes salienta que "A formação de vínculo por si só é algo que desperta medo e ansiedade [...] quanto maior o vínculo, mais dependente eu posso me tornar do objeto" (sic). É evidente, portanto, a vulnerabilidade que as vinculações sempre irão apresentar e essa é uma característica inata aos envolvimentos dos relacionamentos entre as pessoas. Muitos pacientes, segundo dados colhidos, discursam de modo direto apontando que não querem se envolver ou se vincular com nenhuma pessoa, isto é, apresentam claramente a fuga ao contato. Mas, um dos princípios básicos da psicologia está em que o ser humano só consegue se desenvolver plenamente no contato com o outro, na troca realizada nesse contato.

Os indivíduos buscam racionalizar o seu sofrimento para que, assim, se estabeleça uma relação pragmática com as angústias referentes à sua queixa. Designa-se uma lógica de consumo em que prós e contras são levantados e, dessa forma, as circunstâncias são distinguidas de modo concreto. Nesse ponto, evidencia-se que as pessoas têm buscado trazer características que são da ordem subjetiva e, por isso, pessoal, para a ordem objetiva e universal padronizada. Consequente à ideia de racionalização, vem a ideia de gestão e resiliência, ou seja, o paciente tem o "desejo de ter capacidade de sofrer e se recuperar rapidamente" (sic). Fica evidente a falsa ideia de controle e administração de circunstâncias que não estão sob o comando humano racional. E, a grande questão problemática implícita é a tentativa de sofrer menos, mas “com uma cobrança pautada nos ideais e na lógica de performance" (sic), ou seja, nas cobranças do meio.

As queixas levantadas na clínica, segundo os dados, denotam uma frustração tida pelos pacientes em terem tomado consciência de que estão aquém daquilo que esperavam e, com isso, não conseguem responder às suas expectativas de se livrarem daquilo que lhes causa aflição, angústia e medo. Os sujeitos também se apresentam pouco tolerantes em suas relações interpessoais e, por isso, acabam se distanciando, ficando indiferentes e chegam ao isolamento.

Educação, Psicologia e Interfaces, Volume 3, Número 3, p. 79-93, Setembro/Dezembro, 2019. 
O psicólogo clínico deverá proporcionar ao sujeito um ambiente seguro, através do manejo no setting terapêutico, para que ele possa retomar suas questões de sofrimento que podem ter sido minimizadas ou banalizadas no decorrer do desenvolvimento, de acordo com uma das participantes. Para tal, o analista irá apontar a utilização dos mecanismos de defesa para que o sujeito compreenda como eles têm causado impedimento e, juntamente, manifestará a necessidade de realizar algumas modificações de concepções. A partir de então, junto ao paciente serão elaboradas alternativas para o enfretamento que trabalharão em paralelo ao desenvolvimento de recursos e potencialidades que o indivíduo possui, porém que podem estar congeladas. Portanto, o contexto clínico irá buscar fortalecer indiretamente o paciente, sendo esta a função do processo de análise.

O sentimento de medo pautado nas questões do sujeito, de acordo com os participantes, pode ser visto de forma mais branda em sujeitos os quais possuem maior integração nas suas estruturas iniciais. Isto é, sujeitos que estão mais fortalecidos em termos egóicos e de self e, por isso, apresentam mais recursos para lidar com a pressão do ambiente. Uma das participantes exemplifica essa reflexão com um exemplo pertinente. Ela compara o impacto no sujeito da influência externa com um terremoto. Quando ocorre um terremoto todas as construções são abaladas. A diferença do impacto está nos alicerces de cada uma das edificações. Da mesma forma, o meio externo sempre irá influenciar o sujeito de algum modo, a diferença consta na estrutura que cada sujeito apresenta para suportar esse impacto. Indivíduos que vivem pautados em seu falso self estarão mais sujeitos às influências externas. À medida que houver um encontro entre sujeitos que estão pautados em seu falso self, a relação não será verdadeira e espontânea, mas sim de sujeitos que estão tentando se assegurar e que buscam se validar no outro.

O medo pode ser considerado como parte da produção social, através das práticas discursivas da contemporaneidade. Os dados apontam também que há pouco investimento em si mesmo e nas questões internas. Devido a esse investimento primordial no externo, os indivíduos preparam-se para responder às exigências do mundo contemporâneo, que requerem a autonomia e a independência, numa lógica de mercado utilitário. Entretanto, a falta de investimento nas questões de desenvolvimento interno resulta na existência de sujeitos com medo de se tornarem independentes e, assim, de enfrentarem situações de desafio. Esse medo está diretamente relacionado às inseguranças em se tornar autônomo e, dessa forma, em assumir as responsabilidades que 
cabem unicamente ao sujeito. Fica evidente, portanto, que a contemporaneidade auxilia a promover o distanciamento dos sujeitos da sua individualidade, isto é, do autoconhecimento de seus afetos, potencialidades e defasagens que precisam ser desenvolvidas internamente. Essa dependência afetiva e emocional é reflexo do medo do contato com a subjetividade e, contudo, denota a dificuldade que os sujeitos contemporâneos têm em crescer e se desenvolver.

Os apontamentos críticos quanto à população contemporânea, que alguns dos participantes fizeram, diz respeito a geração atual que foi muito poupada às frustrações e, por isso, apresenta dificuldades de enfrentar o mundo real. Pondé afirma que "é inerente ao crescimento enfrentar a dor e a ansiedade" (PONDÉ, 2012, p. 96) para que a pessoa amadureça emocionalmente e, assim, consiga enfrentar as adversidades da realidade através da sua autonomia emocional e psíquica.

Segundo os dados levantados através das entrevistas, a sociedade contemporânea anseia obter o controle de todas as circunstâncias da vida. Por isso, é possível notar uma contradição vivida pelos indivíduos que aspiram por novidades e, em paralelo, permanecem na zona de conforto, em contato com o conhecido, pois, afinal, o desconhecido é assustador. Bauman (2012) destaca a forma como os indivíduos contemporâneos passam a viver almejando esse controle e, juntamente, a eliminação de perigos e como essa ânsia toma conta do modo de viver das pessoas.

Nesse sentido, percebe-se que muitas das angústias e queixas trazidas pelos indivíduos, dizem respeito a uma busca por "controlar aquilo que é da ordem das contingências da vida" (sic). Ademais, é importante ressaltar que quanto mais o sujeito busca o conhecido, mais frágil e vulnerável ele será ao desconhecido, ao desencontro, ou seja, ao contato genuíno com o outro.

Devido às exigências do mundo moderno que pressionam os indivíduos a perseguirem seus próprios interesses e satisfações e a somente se preocupar com os interesses e satisfações dos outros à medida que estes o afetem, as pessoas passam a acreditar que, todos a sua volta também são guiados pelos mesmos motivos egoístas (BAUMAN, 2012). Desse modo, os sujeitos não esperam comportamentos desinteressados dos outros, pois eles mesmos não foram treinados a olhar de forma empática. Numa sociedade assim, os indivíduos sentem-se extremamente inseguros em suas relações e essa percepção pode se tornar endêmica. Essa endemia, por sua vez, exalta 
"a fragilidade crônica dos vínculos humanos e aumenta os temores que essa fragilidade tende a gerar" (BAUMAN, 2012, p. 124).

Uma das participantes discute a questão da influência do ambiente para o sujeito pontuando que "sempre houve influência do meio" (sic), mas a diferença está em que as pessoas da contemporaneidade foram crianças de uma fase que sofreu muitas mudanças sociais. A principal mudança ocorreu na dinâmica familiar, em que a mulher foi para o mercado de trabalho e, com isso, não pôde dar atenção integral à criança. Dessa forma, muitas das necessidades básicas das crianças dessa geração, não foram devidamente satisfeitas. Os dados obtidos indicam que elas carregam em sua personalidade os frutos das diversas mudanças ocorridas na atualidade e na estrutura familiar que impactarão no desenvolvimento delas. Os traços de personalidade, portanto, podem ser mais facilmente influenciados pela situação atual.

Um dos principais fatores da contemporaneidade é a velocidade das mudanças socioeconômicas culturais em tão pouco tempo e também a grande quantidade e velocidade das informações. Nesse contexto, o indivíduo se vê cercado de milhares de possibilidades e ele não dá conta de assimilar todas essas informações e estímulos tão rapidamente e, assim, acaba gerando medo e insegurança. "O excesso de informação e estimulação de vários tipos desestabiliza o sujeito e põe à prova sua capacidade de metabolizar e atribuir sentido à experiência cotidiana, exacerbando uma condição que lhe é inerente como ser falante" (GARCIA; COUTINHO, 2004, p. 10).

As exigências da atualidade têm dificultado a atuação da mãe em sua dedicação para suprir as necessidades do bebê. A partir desse contexto, entra o analista com a função de retomar essas questões em que houve falha do ambiente para poder repará-las e ressignificá-las dentro de um ambiente seguro e confortável.

Os participantes entrevistados, apesar de terem feito apontamentos distintos, acordaram que tanto as questões intrapsíquicas quanto o meio social em que o sujeito vive são essenciais na constituição deste, bem como das questões que ele apresenta como queixa. Os indivíduos se definem a partir das relações, como ressaltado por uma participante, portanto, os seus "mecanismos, conteúdos e organização psíquica sempre vêm da relação com o meio" (sic). Sendo assim, pode-se ressaltar que tanto as relações primitivas irão influenciar o vir a ser do sujeito e como ele irá se organizar e se constituir, quanto o meio social, o tempo histórico e o seu contexto. 


\section{CONSIDERAÇÕES FINAIS}

Como ponto crucial do trabalho desenvolvido pelos psicólogos clínicos, um dos participantes destaca a importância do estudo a respeito do meio e do contexto sociocultural para exercer com eficácia a prática clínica. Estimular o indivíduo a se adaptar àquilo que ele próprio está trazendo como angústia, medo, sofrimento e que está lhe causando adoecimento seria totalmente contrário aos objetivos da clínica que é auxiliar o indivíduo a se fortalecer, para então se desenvolver. Nesse contexto, é preciso se atentar a incompetência cultural, pontuada por um dos participantes, que seria a prática do psicólogo que visa a análise apenas com foco no intrapsíquico, ou seja, que trabalha com as competências exclusivamente internas para alcançar a resiliência.

O trabalho do psicólogo clínico, portanto, tem como foco auxiliar o indivíduo a reconhecer em si e em seu contexto quais os pontos que há de entrave e que, por isso, não permitem o seu desenvolvimento saudável. Contudo, essa prática está longe de ter como objetivo exaurir o sofrimento natural das contingências da vida humana, mas sim auxiliar o sujeito a encontrar em si recursos para remanejar suas dificuldades.

Levando essas questões em consideração, pondera-se que a ânsia em eliminar riscos, em esgotar as possibilidades de erros e frustrações é completamente incoerente com a vida humana. Cabe ao contexto clínico, quando este é buscado de forma ativa pelo indivíduo, acolhê-lo e traçar um plano terapêutico levando em consideração a necessidade daquele sujeito bem como o seu tempo de elaboração das questões a serem cuidadas.

Essa pesquisa, portanto, pôde averiguar que o sujeito pautado pelo medo irá sofrer consequências tanto individualmente, quanto no contato com o outro. Suas relações serão mantidas com certo distanciamento que, consequentemente, o afastarão da autenticidade e originalidade da vinculação. Sendo assim, o indivíduo estará sujeito a um ciclo de repetição de comportamentos e relacionamentos que estará sempre pautado nas mesmas queixas e angústias. Com isso, haverá um impedimento claro em ir ao encontro de novas vivências e novas relações.

Cabe ressaltar também as diversas formas como o medo aparece, sendo possível percebê-lo através de sentimentos de insegurança, angústia, ansiedade, dentre outros. Os profissionais da área clínica, portanto, precisam estar abertos, sensíveis e atentos à forma como os sintomas são suscitados no contexto terapêutico, pois caberá a eles fazer um

Educação, Psicologia e Interfaces, Volume 3, Número 3, p. 79-93, Setembro/Dezembro, 2019.

ISSN: 2594-5343. DOI: https://doi.org/10.37444/issn-2594-5343.v3i3.174 
levantamento das queixas para que assim, sejam capazes de traçar estratégias e o manejo necessário para cada caso.

Esse estudo permitiu explorar diversas características que surgem no contexto clínico que são trazidas como sofrimento pelos indivíduos, que podem ser discutidas pelos profissionais. Por ser uma temática que aborda diversas pautas, cabe pontuar que estudos posteriores podem investigar de modo mais aprofundado a respeito das questões contemporâneas como influência direta sobre os indivíduos; das diferenças que pode haver em tempos remotos sobre a mesma temática; das análises sobre o medo para além da visão psicanalítica e do alinhamento entre o contexto clínico e social imprescindível para um desempenho eficaz da atuação dos profissionais da Psicologia.

\section{REFERÊNCIAS BIBLIOGRÁFICAS}

\section{AMERICAN PSYCHIATRIC ASSOCIATION. Manual diagnóstico e estatístico de transtornos mentais - DSM-V. 5 ed. Porto Alegre: Artmed, 2013.}

ANDRADE, E. O homem vazio: uma crítica ao utilitarismo. Trans/Form/Ação, Marília, v. 36, n. 2, p. 105-122, maio-ago, 2013.

BAUDRILLARD, J. A sociedade de consumo. Lisboa: Edições 70, 1995.

BAUMAN, Z. Sobre a origem, a dinâmica e os usos do medo. Medo líquido. Rio de Janeiro, 2008.

GARCIA, C. A.; COUTINHO, L. G. Os novos rumos do individualismo e o desamparo do sujeito contemporâneo. Psychê, São Paulo, ano VIII, n. 13, p. 125-140, jan-jun, 2004.

GIL, A. C. Como elaborar projetos de pesquisa. 4 ed. São Paulo: Atlas, 2002.

KARNAL, L. Bauman: diálogo da segurança e do efêmero. 2018. Disponível em: <https://www.youtube.com/watch?v=LoxeltkRspY> Acesso em: 18 set. 2018.

LOWEN, A. Medo da vida. Edição integral. São Paulo: Círculo do livro, 1980.

NETO, A. N. Falso self e patologia borderline no pensamento de Winnicott: antecedentes históricos e desenvolvimentos subsequentes. Natureza Humana, São Paulo, v. 12, n. 2, 2010.

PONDÉ, D. Z. F. O conceito de medo em Winnicott. 2012. Dissertação (Mestrado em Filosofia) - Instituto de Filosofia e Ciências Humanas, Universidade Estadual de Campinas, Campinas. 
RIBEIRO, K. C. R.; ABECHE, R. P. C. A repercussão da sociedade de consumo nos vínculos afetivos dos adolescentes. Revista Mal-Estar e Subjetividade, Fortaleza, v. 13, n. 1-2, p. 81-112, mar-jun, 2013.

SAFRA, G. A clínica em Winnicott. Natureza Humana, São Paulo, v. 1, n. 1, jun, 1999.

SANTOS, J. F. O que é o pós-moderno. 1 ed. São Paulo: Brasiliense, 1986

SCHMITT, S.; IMBELLONI, M. Relações amorosas na sociedade contemporânea. 2011. Disponível em: 〈http://www.psicologia.pt/artigos/textos/A0583.pdf> Acesso em: Outubro de 2018.

SILVA, G. V.; LIMA, A. A.; PINHEIRO, N. N. B. Sobre os conceitos de verdadeiro self e falso self: reflexões a partir de um caso clínico. Cad. Psicanálise, Rio de Janeiro, v. 36, n. 30, p. 113-127, jan-jun, 2014.

SMEHA, L. N.; OLIVEIRA, M. V. Os relacionamentos amorosos na contemporaneidade sob a óptica dos adultos jovens. Revista Psicologia: Teoria e Prática, São Paulo, v. 15, n. 2, p. 33-45, maio-ago, 2013.

VANIER, A. Temos medo de que. Ágora, Rio de Janeiro, v. IX, n. 2, p. 285-298, $\mathrm{jul} / \mathrm{dez} 2006$.

WINICCOTT, D. W. Explorações psicanalíticas. Porto Alegre: Artes Médicas, 1994.

WINNICOTT, D. W. O brincar e a realidade. Rio de Janeiro: Imago, 1975.

\section{Credenciais da/os autora/es}

ARAÚJO, Gabriela Monteiro de. Graduada em Psicologia pela Universidade Presbiteriana Mackenzie. E-mail: gabriela.mda16@gmail.com

ALBERTINI, Maria Regina Brecht. Doutora em Psicologia pela Universidade de São Paulo e Professora do Curso de Psicologia da Universidade Presbiteriana Mackenzie. Email: mrb.albertini@mackenzie.br

Endereço para correspondência: Gabriela Monteiro de Araújo. Rua Manguari, 401, bloco C1 ap. 124, Jardim Andaraí. CEP: 02167-080. São Paulo/ SP. E-mail: gabriela.mda16@gmail.com

Como citar este artigo: ARAÚJO, Gabriela Monteiro de; ALBERTINI, Maria Regina Brecht. O impacto do medo nas relações interpessoais. Educação, Psicologia e Interfaces, v. 3, n. 3, p. 79-93, 2019. DOI: https://doi.org/10.37444/issn-25945343.v3i3.174 
O impacto do medo nas relações interpessoais

Recebido: 07/08/2019.

Aceito: 20/11/2019. 